\title{
Bonding Restorative Material
}

National Cancer Institute

\section{Source}

National Cancer Institute. Bonding Restorative Material. NCI Thesaurus. Code C62566.

An adhesive restorative material, available in a number of shades to match patients'

teeth, used for restoring teeth, correcting tooth discolorations, or cosmetic tooth enhancements. 